\title{
CONSIDERAÇÕES METODOLÓGICAS DE UMA PESQUISA ENTRE O ARTÍSTICO E O PEDAGÓGICO: DA EXPERIÊNCIA À RECOLHA DOS TRAÇOS ${ }^{i}$
}

Victor Junger ${ }^{\mathrm{ii}}$

\begin{abstract}
Resumo
Este trabalho objetiva apresentar algumas considerações sobre o método que puderam amparar minha pesquisa de mestrado em sua tentativa de elucidar as experiências vivenciadas como acontecimento de criação. Nesta meada que pôde ser empreendida junto aos dispositivos pedagógicos e artísticos, articulam-se as reflexões no limite entre um campo de ordem fenomenológica e um procedimento de análise dos dispositivos. Procuro de maneira sumária apresentar esta articulação entre estes dois campos pela noção de traço, para em seguida pensar como a pesquisa incorporou os dispositivos pedagógico e artístico em suas considerações.
\end{abstract}

Palavras chave: Metodologias; Dispositivo; Acontecimento de Mundo; Aprendizagem; Criação.

\begin{abstract}
This work presents some considerations about the method that might support my master's research in its attempt to elucidate the experiences as a happening of creation. This hank that could be undertaken together with the pedagogical and artistic dispositif, the reflections are articulated on the edge between a field of phenomenological order and a procedure of dispositif analysis. I look for to present briefly this articulation between these two fields by trace notion, to then think how the research incorporated the pedagogical and artistic dispositifs in their considerations.
\end{abstract}

Keywords: Methodologies; Dispositif; World Happening; Learning; Criating.

As pesquisas que privilegiam o vivido em suas formas de apreensão terminam por evidenciar o cotidiano dos mundos em pleno e corrente desvelo. Enquanto investigam a originalidade do saber realizado no cotidiano, é o próprio movimento de atualização que vicejam através dos registros do vivido. Estariam as pesquisas do cotidiano e as pesquisas narrativas de tal modo voltadas para as experiências passadas que não se furtariam a apresentar o sorrateiro 
desvelamento dos mundos. São os movimentos de atualização dos corpos e das coisas que se dariam por expresso em sua procura pelo saber desempenhado na experiência.

Teríamos por expresso o enervamento epidérmico que é a raiz do mundo, como o sensível que é o próprio corpo percebido pelo sentido das coisas. Perceberíamos a mudança antes tão diminuta e menor atravessar o horizonte da paisagem figurada. Avançar pela superfície dos objetos com uma nova tonicidade tangível. A camada espeça dos cotidianos ${ }^{\mathrm{iii}}$ sorrateiramente mudando o tom, a gravidade de suas cores, expressando com isto que sentimos uma nova sensibilidade. E, como de súbito, encontraríamos nesta visada novas formas de existência, modos de ser e estar no mundo, cujas sensibilidades se dispõem como outras pelo desdobrar do acontecimento.

Seriam os mundos ${ }^{\text {iv }}$ herdeiros destes movimentos revelados em sua íntima renovação. Sendo o mundo compreendido como a atualidade extensiva do que pode ser dito, visto e sentido ${ }^{\mathrm{v}}$, seu desvelamento nos aconteceria justamente sob estas formas de apreensão radicadas nos encontros entre os corpos e as coisas. Perceberíamos de outro modo a paisagem figurada pela intensidade com que se refaz nosso contato com o sensível. Vivenciaríamos a renovação de sua abertura pela diferença que nos acontece sorrateira a cada instante. As pesquisas que privilegiam o vivido em suas formas de apreensão terminam por ceder, declinar ou estender nosso envolvimento através daquilo que pretendem elucidar em seus registros.

Mas a apreensão do vivido somente seria possível através dos traços que ainda persistem em sobreviver ao movimento de atualização dos mundos. Somos surpreendidos no presente pela profusão que antes mobilizou a passagem do acontecimento. E, como que de repente, tomamos a paisagem existencial pelos traços que evidenciam a mudança realizada no entrecruzamento de suas aberturas. Desvelamos a atualidade do momento pelas marcas que indiciam a antiga filiação de nossos pertencimentos. Encontramo-nos expostos pelos rastros em que pudemos ser no passado dos mundos. Nosso estranhamento possibilitaria tomar a permanência dos traços como forma de elucidação do vivido. O estupor nos permitiria aqui interrogar as aberturas de mundo gestadas pelo acontecimento.

Se as pesquisas narrativas e do cotidiano procuram investigar os saberes desempenhados na experiência, não lhes restaria recorrer em seu percurso senão àquilo que se deu como impresso pela atualização dos movimentos evenemenciais ${ }^{\text {vi }}$. A profusão de sentidos advindas do acontecimento, como também aqueles nascidos em outras ocasiões, são agora entre os edifícios, instalações e objetos os remanescentes de sua passagem. Desvelamos a atualidade de nossa condição pelas marcas que, entre as superfícies e os objetos, dariam por expresso a renovação dos mundos passados. São os traços que tornariam possível o prolongamento do acontecimento como problema a ser vivenciado na atualidade do momento. 
Nesse sentido, este trabalho objetiva apresentar algumas considerações sobre as metodologias que puderam amparar minha pesquisa de mestrado em sua tentativa de compreender as experiências vivenciadas como acontecimento de criação. Mais precisamente de que modo estas considerações de método puderam amparar as narrativas, fotografias e análises a respeito de minha estada em campo e sua consequente intervenção, nesta meada que pôde ser empreendida junto a dispositivos pedagógicos e artísticos, preparando as condições de possibilidade para apreensão e emergência de um acontecimento de criação de mundos.

As reflexões desenvolvidas se articulam ao mesmo tempo no limite entre um campo de ordem fenomenológica e os procedimentos de análise dos dispositivos ${ }^{3}$. Este limite tem sido compreendido como um pensamento do traço que, no primeiro caso, seria elaborado em sua relação extrínseca com outros mundos, e no segundo pelos acidentes e acontecimentos estranhos às regularidades do dispositivo. Procurei me afastar respectivamente tanto de uma possível redução de nossas vivências à totalidade do mundo ${ }^{4}$, e com isso de sua antecipada celebração, quanto de uma recusa em contemplar os acidentes sofridos pelas regularidades de saber, tomando o dispositivo como estrito condicionante de nossas relações.

Os procedimentos metodológicos se dispõem nesta região limítrofe onde percebemos a nós mesmos imersos no mundo enquanto na sua exterioridade apreendemos os traços evenemenciais. A tensão constitutiva desta região é melhor esclarecida por Didi-Huberman (2013) quando, voltado no espaço da pintura para a noção sintomática de trecho, encontra aí a possibilidade de escapar tanto às totalizações do campo fenomenológico quanto às reduções dos procedimentos semiológicos. Didi-Huberman enseja empreender uma história das torsões e dos desvios, escapando de seus aspectos fantasmáticos nisto que é permanentemente reiterado pela pintura, para associar-se de pronto à análise tópica dos sintomas que não cessaria de remeter seus enunciados a uma estrutura subjacente. Sua proposta de trabalho consiste em restituir à historiografia seu caráter estrutural pelo enfrentamento daquilo que persiste em se dispor como estranho e acidental.

Entretanto, ao contrário de tomar parte dos componentes estruturais revelados por seu aspecto sintomático, procuro manter a discussão sob a noção de traço em sua relação com os dispositivos de poder. Nesse caso, me aproximo das contribuições da análise arqueológica de Foucault (1972) como do paradigma indiciário de Guinzburg (1989), que apontam para elementos discretos como fundamentalmente formadores de um determinado campo discursivo. Tomando o traço como pertencente às cadeias discursivas, não seria ele nada mais que o limiar de existência dos signos, cuja amplitude envolveria tanto aos indícios que deliberadamente remontam ao conjunto de um todo, quanto aos rastros perturbadores de uma fissura. O que para Didi-Huberman 
poderia distinguir o detalhe do trecho, respectivamente a parte de um campo representacional e o elemento sintomático de uma crise, seria aqui diluído sob a rubrica dos traços evenemenciais sem pretender destituí-los de sua diferença essencial. Antes, preocupa-me o escrutínio dos traços em sua absoluta distinção como a possibilidade não expressa de instaurar o plano do direito sobre o plano dos fatos e, assim, a possibilidade de erigir em importância um conjunto de experiências em detrimentos de outro igualmente importante.

Além disso, é o modo como relaciono os traços aos procedimentos metodológicos que me distancia das contribuições de Didi-Huberman. Não se poderia negar a relevância de suas críticas quanto aos dispositivos simbólicos que, ao exercerem em demasia seus rudimentos ${ }^{\mathrm{vii}}$, terminam por transpor para as formações discursivas uma única expressão de nossa experiência de mundo, onde se percebe aí o risco de abafar tudo o que seja pregnante de sentido, e fiel a uma modalidade de enunciação o pouco que pode ser expresso do muito que se pretende dito. E, sendo este risco sempre eminente quando se procura elucidar o vivido, convém conduzir os dispositivos pelo que se é percebido no âmbito da experiência cotidiana, onde justamente excedem nossas possibilidades de compreensão dos acontecimentos de mundo. Quando o autor recorre ao sintoma como forma privilegiada de apreensão das condições estruturais da pintura, desloca neste mesmo movimento seu olhar dos rudimentos metodológicos, suas impossibilidades e restrições, para o que se insinua no acontecimento subjacente aos mundos que, longe de se manifestar, permanece oculto por trás de toda a aparição sensível. Contrariamente, ao associar o traço evenemencial às formações discursivas do dispositivo, é o próprio contato entre os procedimentos metodológicos e os acontecimentos de criação que não deixam de ser interrogados pela pesquisa.

Quando reitero a importância de se partir dos dispositivos de poder, no menor de seus exercícios que é a recolha dos traços evenemenciais, procuro assim estender para as formas de enunciação, para as formações discursivas, o problema deste contato imediato e ocasional com os acontecimentos de criação de mundo. Isto, pois, equivale a interrogar os procedimentos metodológicos no âmbito mesmo da experiência de apreensão dos sentidos. Mas, situado em relação à crítica realizada por Didi-Huberman, ter a condição de mundo própria ao campo fenomenológico como forma de ampliar os empreendimentos dos dispositivos de poder, estendendo seus procedimentos para aquilo que lhe escapa e excede no cotidiano dos mundos. Dessa maneira, na articulação entre o campo fenomenológico e o procedimento de análise dos dispositivos, estão os traços que se dispõe como ranhuras permanentemente provocadas pelos acontecimentos às regularidades discursivas. Conforme emergem singularidades que não cessam de provocar torsões e desvios no que ainda se faz existir, terminamos por reconhecer o acontecimento de mundo por esta resistência que exercem as regularidades do dispositivo. 
Assim, procuro apresentar sumariamente a articulação metodológica entre estes dois campos pela noção de traço, para em seguida pensar como minha pesquisa de mestrado incorporou os dispositivos pedagógico e artístico em suas considerações. Tendo destacado a importância da noção de traço, procuro expor como pôde se encaminhar na experiência para preocupações de ordem metodológica, e então encontrar na análise dos dispositivos a orientação favorável ao percurso investigativo. Em seguida, tomando a análise dos dispositivos como fundamental para os desdobramentos da pesquisa, apresento de forma sumária os dispositivos acionados no curso da pesquisa a partir daquilo que puderam nos amparar em seu modo de apreensão da experiência vivida.

Certo de que a recolha dos traços evidencia os movimentos de atualização pelos quais deixamos de ser no mundo, não se poderia ignorar ao longo do percurso investigativo os métodos pelos quais aprofundamos nosso engajamento junto aos cotidianos estudados. A própria pesquisa exigindo assim um trajeto que proceda a recolha dos remanescentes da experiência ${ }^{\text {viii }}$, não constituiria ela mesma um movimento de elucidação da experiência sem também problematizar o modo como são conduzidos os percursos investigativos. O cuidado com que conduzimos o dispositivo investigativo se dispõe na experiência como expressão de nossas exigências metodológicas. E pelo cuidado com que procedemos nossa entrada nestes cotidianos, entre aqueles que habitam os espaços pesquisados, estaríamos em condições de perceber o menor movimento de atualização dos acontecimentos, como de apreender as criações e aprendizagens pelas quais se desdobram os efeitos evenemenciais.

No sentido de garantir que nosso envolvimento possa se realizar na cotidianidade dos mundos, aprofundar as junturas de nosso contato, conviria por método nos acercarmos dos efeitos de que padecem, usufruem ou cedem as comunidades estudadas. Não se poderia querer pesquisar outras sensibilidades de mundo sem que se tomasse parte de seus dramas, prazeres e aflições. Não se poderia pretender estudar outros modos de ser e estar no mundo sem que também fossem compartilhadas suas possíveis experiências de pertencimento. Se o percurso investigativo nos exige compartilhar as experiências de uma determinada comunidade, este movimento não poderia senão nos conduzir à iniciação de nosso pertencimento a suas aberturas de mundo. Pertenceríamos assim a uma mútua sensibilidade dos gestos e palavras pelo envolvimento com que nos dispomos a realizar estas experiências comumente partilhadas. Formaríamos pela sensibilidade de nossas vivências os cotidianos de mundo próprios à pesquisa.

Mas seria igualmente necessário tomar por método o envolvimento que nos assegure a apreensão compartilhada dos acontecimentos, já que, ao diluir as fronteiras de nosso pertencimento passado, a pesquisa se veria atravessada pelos gestos, ações e palavras de parte da 
comunidade. Se não criássemos as condições para percepção destes movimentos de atualização, pouco se poderia elaborar junto aos desdobramentos efetuados pelo acontecimento. Se não considerássemos as mudanças realizadas por nossa iniciação entre as aberturas de mundo, pouco se poderia apreender de qualquer experiência vivida entre os participantes da pesquisa. Sendo um processo elucidado no âmbito do coletivo, vivenciado em íntima proximidade com a comunidade estudada, é o próprio contato que estabelece a tônica de seus procedimentos de recolha dos traços evenemenciais. Como o próprio contato que atravessa as análises elaboradas após a acumulação dos traços nesta regularidade que seria do saber desempenhado na experiência.

A intensidade com que se manifesta o contato com a comunidade estudada, o estupor e o estranhamento que frequentemente o acompanham, termina por evidenciar a problemática do pertencimento a que está sujeito todo o percurso investigativo. Conforme nos detemos ou prolongamos os efeitos de sua aparição, tomamos por cuidado metodológico os sentidos de sua manifestação, o percurso da pesquisa se faz como um processo iniciático em que a aprendizagem dos mundos expressa o saber de pertencimento a estes mesmos mundos, como a uma trama em que desvela as agruras e os prazeres, os problemas e implicações, de ser parte de uma determinada comunidade. Ao lado dos progressos que possam ser feitos, são as sensibilidades de mundo que possibilitam esta proximidade dos sentidos, a percepção dos dramas e prazeres, o saber que na experiência pesa àqueles de que se investem no cotidiano dos mundos. $\mathrm{O}$ cuidado metodológico se traduz aqui como este cuidado em atravessar e permanecer nas aberturas de mundo próprias à comunidade, e que inevitavelmente desvelam os mundos igualmente próprios ao dispositivo investigativo.

Sendo a intensidade com que percebemos este contato efeito de acontecimento, o cuidado em avançar por outros mundos estaria longe de nos impedir de realizar qualquer acontecimento que nos possibilitasse pensar as sensibilidades já estabelecidas entre a comunidade estudada. $\mathrm{Na}$ medida em que nosso contato com o cotidiano dos mundos estudados implica necessariamente um movimento iniciático, o percurso investigativo estaria destinado ele mesmo a produzir uma sucessão de acontecimentos de atualização de mundo. Não seria equivocado, pois, tomar para o dispositivo investigativo a tarefa de realizar de forma deliberada um acontecimento em que se possa ter como questão os interesses de pesquisa. E dessa maneira ter um acontecimento que, desvelado por nossos gestos, nos possibilitasse acompanhar na alçada de seus efeitos diferentes processos de aprendizagem e criação.

Assim, o cuidado metodológico adviria também de nossa preocupação em elaborar através de determinadas ações as condições de possibilidade para a emergência do acontecimento. Mas de uma maneira que não deixamos de ser afetados por nosso engajamento, envolvendo-nos nesta 
preparação que é a do acontecimento de criação por meio de análises sobre a própria condução do percurso investigativo. De modo que os efeitos evenemenciais que nos são o problema atual ainda possam ser desdobrados como a preparação de um acontecimento futuro, nossas preocupações acerca do método exigem a análise do percurso junto às aprendizagens e às criações que se realizam como intimamente radicadas nos movimentos de atualização. A pesquisa então se veria em condições de realizar este empreendimento votado a perturbar as sensibilidades vigentes em prol de algo que por outras vias nos permitiria recriar e aprender seus entrecruzamentos.

O dispositivo, que é no tempo o abrigo dos traços remanescentes, nos permitiria dizer do acontecimento a existência de sua passagem. Através de suas malhas percorreríamos no presente momento o que, pelo vínculo com o passado, deixamos de ser entre edifícios, instalações e objetos. Estaríamos em condições de comunicar a experiência vivenciada no passado e a singularidade do tempo presente, como insistir também nestas possibilidades de entendimento que ainda vicejam seu porvir. Encontraríamos na extensão de suas regularidades as condições de possibilidade do vivido a partir de um entendimento parcial e momentâneo das nossas experiências passadas. A apreensão dos traços se conjuga aqui ao procedimento de análise das condições que, neste contato com o dispositivo investigativo, torna o acontecimento perceptível.

A análise desenvolvida pela acumulação dos traços tem o percurso investigativo como forma de garantir o envolvimento e a apreensão do acontecimento de criação. Tendo os traços como o limiar de existência dos signos, a análise adquiriria por sua recolha a compreensão provisória e parcial dos acontecimentos pelos quais se atualizam os mundos. A análise tornaria compreensível a cadeia que comunica as diferentes aberturas de mundo a partir das regularidades próprias ao dispositivo investigativo.

E, para tanto, seriam consideradas as narrativas, imagens e fotografias a efetuação dos traços impressos pela passagem do acontecimento de criação. O que haveria de nos reservar a recolha dos traços neste percurso pelos mundos senão as narrativas e imagens realizadas como os remanescentes do acontecimento, expressas na paisagem existencial, ainda presentes como os desdobramentos daquilo que pôde ser vivido conjuntamente no coletivo. Ao considerar a acumulação e recolha dos traços da experiência também como produção de narrativas e de imagens, as considerações metodológicas apresentadas não se fariam como regularidade senão a partir deste cuidado em percorrer os cotidianos empreendendo a captura de suas visadas, como elaborando também a narrativa de nossas vivências. Seriam elas pensadas pela problemática de todo o percurso que ensejaria ser narrado a medida que o desvelo da experiência progride entre diferentes sensibilidades de mundo. 
Haveria de nos interrogar em nossos encontros cotidianos sobre o que foi e o que será através da análise de nosso percurso pelas aberturas de mundo. E, no movimento de interrogação, forjar também como narrativas os remanescentes de que constituem as regularidades próprias a cada dispositivo. A análise realizada pela acumulação teria as narrativas, as fotografias e as imagens como parte deste envolvimento com o acontecimento de criação. São as narrativas e imagens o modo como pôde se realizar a apreensão daquilo que intimamente persistimos em ter como vivido. O dispositivo investigativo assim se vê constituído tanto pelas narrativas e imagens realizadas na experiência quanto pelas análises que as reúnem em regularidades extensivas. É dessa maneira que as preocupações metodológicas exercem em sua relação com o acontecimento a cuidadosa composição de um dispositivo investigativo.

Sendo o objetivo principal de minha pesquisa de mestrado investigar os acontecimentos de criação da escola na sua relação com as visibilidades de mundo, o envolvimento com seu campo problemático acionou formas de apreensão da experiência visual que, de algum modo, realizariam regularidades de saber intimamente radicadas no contato com os estudantes. Circunscrita aos cotidianos de um colégio ${ }^{\text {ix }}$ da rede pública de ensino, localizado no centro da cidade do Rio de Janeiro, a pesquisa transitou por estas criações efetuadas ao sabor dos encontros com os estudantes, conforme aprofundava nosso engajamento, também pôde exercer com mais cuidado sua compreensão acerca do espaço de vivências da comunidade. Parte do problema que se fez presente na pesquisa, e caracterizaria os demais desdobramentos investigativos, foi como envolver-se entre os diferentes modos de ser e estar na escola, suas produções eminentemente visuais e poéticas, sem reduzir e minorar os efeitos que se realizariam em potência de contágio.

De início a pesquisa se viu envolvida em problemas relacionados com seu pertencimento aos cotidianos escolares. Foi neste momento fundamental frequentar assiduamente os cotidianos para se pensar a via de preparação do acontecimento de criação. Parecia estar claro nas primeiras semanas que este processo somente ganharia sentido se o dispositivo investigativo destinasse seus investimentos ao nível do contato com os estudantes. A preparação do acontecimento consistiu em garantir a maior participação dos estudantes, enfrentando com eles os seus dramas de aprendizagem e criação, seus incômodos e estranhamentos, promovendo durante a elaboração da pesquisa o fortalecimento de suas produções. Quando já envolvidos com a proposta de trabalho em fotografia, os grupos pareciam explorar os espaços escolares a partir de trajetos antes inusitados, atentos a percursos em que pudessem presenciar novas visadas, como igualmente confiantes em manejar os recursos da câmera e do enquadramento. O problema de nosso pertencimento aos cotidianos escolares se confundia progressivamente com o problema da 
preparação do acontecimento, tendo conjugado as visadas impressas em fotografias com a progressiva apreensão do que poderia nos alcançar como experiência ainda porvir.

Num segundo momento a pesquisa se voltou para o modo de apreensão do acontecimento por parte de toda a comunidade. Seria importante compreendê-los a partir do engajamento da comunidade escolar para com o campo problemático e, neste mesmo movimento, ter pelos investimentos destinados às imagens fotográficas o sentido mesmo dos modos de apreensão compartilhados. Composta por oitenta e uma fotografias dos cotidianos do colégio, a ocupação imagética concentrou parte destas imagens em uma instalação confeccionada por fios vermelhos no centro do primeiro pavimento, distribuindo o restante delas por entre paredes, banheiros, refeitório, corredores e quadra de esporte. Os estudantes que produziram estas imagens estariam livres para concentrá-las em um determinado ponto ou expandi-las para as demais áreas do colégio, fazê-las se perder em algum corredor ou destacar sua presença pelas vias de maior circulação no colégio. A atualização do acontecimento teria, pois, como índice o destino investido pelas imagens, as pequenas resoluções perpetradas neste encontro com sua superfície, o prolongamento de seus efeitos entre diferentes gestos e outras superfícies.

Assim, a pesquisa foi em grande parte pensada a partir dos dispositivos que viriam a ser acionados pelo acontecimento de criação, deflagrando a um só tempo outras formações de saber e campos de visibilidade numa tentativa de compreender o desvelo da experiência. Através do acontecimento efetuado nos cotidianos do colégio, duas áreas do conhecimento seriam evocadas durante o percurso investigativo a fim de elucidar as aprendizagens e criações empreendidas pela comunidade escolar: a educação como modo de evidenciar num coletivo o problema da realização do saber; a arte como modo de compreender no sensível o problema da experiência de criação.

Foram estas áreas do conhecimento humano que nos possibilitaram pensar e elaborar o modo de acumulação dos traços. Foram os seus respectivos regimes de apreensão e de verdade que nos ofereceram as condições de possibilidade para ver e saber aquilo que, pelo exercício de cada dispositivo, nos envolvia em meio acontecimento de criação. Tal como uma meada de dispositivos que não cessa de exercer o acúmulo dos traços, a pesquisa não seria apenas capaz de apresentar os movimentos de atualização dos cotidianos, como também tornaria possível uma análise complexa e difratada dos diferentes encadeamentos do percurso investigativo.

Corresponderia à área de educação o saber das aprendizagens elaboradas por um determinado grupo. Ela seria responsável pela recolha e perpetuação dos traços que nos permitem reconhecer o saber desvelado por um determinado coletivo ${ }^{\mathrm{x}}$. Através destes processos de acúmulo e reprodução é possível ter acesso na alçada dos mundos à aprendizagem do saber relativo ao seu campo problemático. O dispositivo pedagógico se ocupa dos rudimentos pelos quais os gestos, as 
imagens e as falas do outro seriam associados a um determinado saber acerca do problema, bem como a realização pelo outro deste saber que se refere à sua própria aprendizagem ${ }^{\mathrm{xi}}$ através dos traços inscritos na paisagem figurada.

No entanto, seus rudimentos se veriam intimamente comprometidos com o processo de transmissão de conhecimento e com a redução do saber da experiência. É próprio dos dispositivos pedagógicos vigentes exercerem a operação judicativa responsável por determinar a distância entre a matéria ensinada e o sujeito aprendiz. Operação que, a um só tempo, impõe e abole esta distância pretensamente determinada acerca da aprendizagem, tomando-a como o principal motivo de sua interrupção ou de sua insuficiência, como instaurando a partir de sua determinação os exercícios de acúmulo e transmissão de saber. Formam-se em suas regularidades os conjuntos de signos que permitiriam apreender tanto a aprendizagem quanto a ignorância, como privilegiar um modo próprio de conduzir a operação, procedimento didático, que ensine tudo a todos.

Restaria à aprendizagem ser intermediada pela disciplina, neste próprio modo de aquisição do conhecimento, seguir rigorosamente a explicação dos raciocínios, identificar seus elementos centrais, exercitar suas soluções a ponto de apenas expressar aquilo que possa ser reconhecido. Resta-lhe adquirir o que já se tem por conhecido e não mais envolver-se com as ambivalências da experiência. Não mais vagar ao sabor de seus desconhecimentos. Nem mesmo tomar para si a cegueira de suas percepções. Os dispositivos pedagógicos instituídos procurariam normatizar precisamente a gênese de doação de sentido, exercendo eles mesmos a disciplina a partir das regularidades que tornam os traços e os escritos integralmente parte do domínio das certezas. Adquiria eficácia o empreendimento disciplinar quando garantida a cegueira constitutiva da norma, de seus esquemas de validação, realizando assim uma ampla região de inexistências.

Certo de que minhas preocupações metodológicas deveriam aqui me conduzir a formações de saber que não poderiam ser apreendidas pelos dispositivos instituídos, elas mesmas coincidiriam com minha tentativa de pertencer à alçada dos mundos de que constitui a escola. Não poderia compreender os saberes desempenhados na experiência, se ainda me mantivesse sob as distribuições discursivas e visuais que instituíram na tradição ocidental a espacialidade escolar. O aprofundamento dos liames que me unem aos estudantes depende intimamente do modo como o dispositivo investigativo procuraria redistribuir esta articulação entre o visível e o dizível nos cotidianos escolares. Estas considerações me permitiram reorganizar frente ao dispositivo pedagógico o lugar de quem vê e quem tem condições de dizer o que viu, quem deve perceber e expressar aquilo que percebeu. Além de ter no percurso investigativo o cuidado para que as distribuições pertencentes aos dispositivos vigentes não exerçam sua lógica de redução e 
transmissão dos saberes, a distância entre quem diz e sente na experiência, sob a recolha e o acúmulo dos traços pertinentes à pesquisa.

Deste cuidado com o percurso investigativo outras aprendizagens poderiam advir para além dos processos de transmissão de conhecimento e de redução do saber. A análise que tem os traços do saber desempenhado na experiência seria responsável por orientar o dispositivo investigativo em suas possibilidades de contágio a partir das produções dos estudantes. Ela mesma problematizando seus exercícios frente aos procedimentos dos dispositivos pedagógicos cujas formações de saber se percebem desobrigadas das ambiguidades e oscilações da experiência. As preocupações de método quanto aos aspectos pedagógicos atuam no âmbito das formações de saber de modo a elaborar regularidades intimamente envolvidas com aprendizagem do acontecimento.

Corresponderia à área da arte as condições de um estado possível à recriação de outras sensibilidades de mundo. Ela se vê comprometida com a inteligibilidade de seus objetos a partir do reconhecimento no sensível dos traços de criação. Como através desses processos de acúmulo e reprodução dos traços é possível também encontrar a criação do sensível impressa na paisagem existencial. O dispositivo artístico nos possibilitaria perceber com sua discursividade histórica a sensibilidade que o gesto de criação teria como visada de um determinado problema. Assim como a atualização pela obra desta sensibilidade que se refere à sua própria criação através das marcas impressas na alçada dos mundos.

Mas as formas instituídas de compreensão da arte estariam em grande parte comprometidas com sua redução pelo campo da história, já que não poderiam elas senão contemplar o objeto de arte pelo que nos é apenas visível. Ela oferece as condições de possibilidade para o que consideram criar novas sensibilidades de mundo a partir de uma histórica hierarquização dos objetos de arte. A formação da sua consciência histórica autorizou às diferentes instâncias do dispositivo determinar a origem desta temporalidade da obra, sua universalidade no tempo, a temporalidade em que se desenvolve a sua produção. Ela mesma o fez restringindo a emergência dos mundos à convergência de um único instante, sua consagração pelas mãos do artista, este instante que não passaria de uma manifestação da ascese originária dos sentidos.

O dispositivo artístico procurou também prever a integridade visível do objeto artístico a partir de uma ampla redução dos traços de sua experiência de criação, levando suas regularidades à perda da organicidade da obra e, dessa maneira, à morte do desvelo no curso dos acontecimentos. A história da arte terminou assim por destinar à mortificação o remanescente artístico, abdicando dos traços paradoxais, de modo a decretar seu ressurgimento como objeto plenamente reconhecido ${ }^{x i i}$. Nem mesmo a tarefa que na contemporaneidade é imputada à arte parece escapar 
ao testemunho de um pensamento que, ao enfrentar sua extinção, procura representar irremediavelmente o irrepresentável.

Na cena contemporânea investe-se o dispositivo artístico, organizado em torno dos modos de ser específicos ao objeto de arte, nesta multiplicidade própria à experiência de criação a fim de afastar da obra a sua antecipada destinação à morte. Antes, o dispositivo enseja fazer coincidir as novas formas de vida com as formas de arte, as distribuições de que se valem as comunidades e as suas regularidades, os entrecruzamentos de suas vivências e de suas formações de saber. É com demasiado cuidado que, atualmente, os dispositivos artísticos lançam mão da história da arte, fazendo uso de suas cadeias de signo, menos para outorgar a seus objetos o estatuto de arte do que propriamente investigar as fronteiras da experiência artística.

Como forma de me conduzir a outras sensibilidades não legitimadas pelos dispositivos instituídos, minhas preocupações metodológicas terminaram por se voltar a uma proximidade de contato com os estudantes a fim de perscrutar suas criações de mundo. Pouco se poderia compreender de suas criações, se não permitisse empreender novos arranjos entre o sensível e o dizível estranhos à visibilidade instituída pela tradição ocidental no espaço escolar. Os dispositivos que, a esta altura, interessam ser avaliados condicionam o que compete ser a criação destas sensibilidades por meio de uma antiga hierarquização dos remanescentes evenemenciais. Se não fosse possível efetuar a criação de suas sensibilidades de mundo, as formações de saber ficariam impossibilitadas de desenvolver na experiência suas respectivas regularidades.

Tais considerações me permitiriam pensar no âmbito da comunidade escolar a possibilidade de perturbar as sensibilidades vigentes e, com elas, as criações comprometidas com o espaço institucional. Além de ter por método o cuidado para que as distribuições pertencentes aos dispositivos artísticos vigentes não exerçam o esvaziamento dos processos de criação a favor de uma incondicional celebração do objeto estético. Os dispositivos artísticos ofereceriam as condições de possibilidade a partir de uma hierarquização dos objetos de arte instituindo procedimentos de legitimidade da criação estritamente articulados à materialidade dos remanescentes. Os atravessamentos com o dispositivo investigativo garantiriam a deflagração de sua diferença histórica pela recolha dos traços e, com ela, o porvir de outras sensibilidades. As preocupações de método quanto aos aspectos artísticos atuariam na alçada dos campos de visibilidade a fim de realizar as regularidades envolvidas com a criação do acontecimento pela redistribuição de quem recria o sensível e quem desvela seus sentidos ${ }^{x i i i}$.

Mas, desde já, uma meada de dispositivos que não somente realizem as condições de possibilidade de um estado de arte, de uma possível recriação das visibilidades, como possam também esclarecer de diferentes modos as experiências mutuamente vivenciadas, além desta 
recriação dos sensíveis que nos permitem ver o campo visual instituído por vias antes inesperadas. Quando desobrigado de atender as partilhas exercidas pela história da arte, o dispositivo artístico nos impulsiona a explorar sem maiores pretensões a cotidianidade escolar, ela mesma como uma multiplicidade de espaços propensos à criação, conduzindo-nos ao insólito de suas existências, como a um especial cuidado com os instantes evenemenciais. O dispositivo artístico nos convida aqui a recriar nossa entrada nos mundos a partir deste contato, inusitado ou arbitrário, com os pequenos irisar dos acontecimentos. Nossa arriscada tentativa de tomar o vivenciado por uma poética de existir.

E se os dispositivos são pensados na pesquisa como uma meada de regularidades, isto ocorre menos por percebê-los integrados no curso de seus procedimentos, este possível anseio de determinar por completo o que nos acontece, do que propriamente seguir os indícios oferecidos por cada dispositivo, sua suposta prevalência em algumas ocasiões do cotidiano, para vasculhar os gestos que o ultrapassam, implodem ou retém os processos já instituídos. O que vem a ser narrado não se pode abster de inscrever em suas regularidades as análises envolvidas em nosso percurso pelos cotidianos, como ter nas narrativas a apreensão de mundo que excede as regularidades dos dispositivos. Conviria, dessa maneira, imbricar as narrativas, as fotografias ${ }^{\mathrm{xiv}}$ e as análises situadas aos contextos de modo a esclarecer com cuidado as dinâmicas da pesquisa.

Importante pontuar que as análises empreendidas não poderiam dissecar a experiência sobre as formações dos dispositivos mencionados. Os imbricamentos entre narrativa e análise seriam realizados no sentido de apresentar por quais vias algumas atuações se mostraram mais apropriadas à problemática do contexto. Se ocorre prevalecer na alçada dos mundos procedimentos relativos a um determinado dispositivo, se esta prevalência é estabelecida em detrimento dos demais processos vividos na experiência, as análises poderiam em alguns momentos nos auxiliar com indícios capazes de desvelar outros mundos possíveis a seus impedimentos e retenções. Os imbricamentos entre narrativas, fotografias e análises seriam realizados ao sabor de cada ocasião, em resposta àquilo que ensejava impedir seus processos de efetuação. Acredito que as narrativas e fotografias se tornam dessa maneira fundamentais na percepção dos movimentos vivenciados entre os cotidianos, seus desvios de rota e seus pequenos gestos, na medida em que também compreendem a intensidade de nossas atuações para com os mundos que se revelam e prolongam em desvelo. Tanto as narrativas e as fotografias não cessariam de apreender o movimento dos corpos realizado nos mundos.

Isso estaria longe de significar que o exercício dos dispositivos seria capaz de condicionar plenamente a elaboração das narrativas e das análises. Não se poderia pretender reconhecer os traços evenemenciais absolutamente convertidos em suas cadeias de signos neste entrecruzamento 
de regularidades. Certo de que ocorre considerar pelo movimento da análise inúmeros dispositivos em pleno exercício na cena contemporânea, eles mesmos imprimindo seus procedimentos de domínio e controle sobre os efeitos do acontecimento, como estendendo a partir da reprodução dos traços a possibilidade de contato com outras aberturas de mundo. As formações de saber realizadas em sua relação com o outro a partir do dispositivo pedagógico. Os campos de visibilidade efetuados nesta recriação dos mundos a partir do dispositivo artístico.

E ainda aqui, implicada pelos dispositivos, as considerações acerca das metodologias se voltariam para a gênese de doação de sentido. A análise não nos furtaria a tomar as regularidades através disto que persiste em sobreviver na alçada dos mundos. Aprendemos diante dos procedimentos de dominação e controle a sua impossibilidade de determinar absolutamente nossas ações. Aprendemos ao ritmo em que se narra a experiência de nossos movimentos entre os corpos e as coisas. Narramos as experiências através desta descontinuidade em que surgem os instantes evenemenciais. Criamos nesta visibilidade o sensível com que aprendemos em narrativas.

As regularidades que minha pesquisa de mestrado procurou apresentar compreendem imagens fotográficas, narrativas e algumas análises que, à sua conta, não pretenderam se afastar deste olhar menor da experiência. Foi sua intenção ao seguir estas considerações metodológicas menos compor um retrato fidedigno do vivido que propriamente a de apresentar os seus caminhos e dramas. Isto, sim, fazer desta apresentação em regularidades descontínuas o remanescente do acontecimento de criação, seu campo problemático, recriação da escola. Remanescente desta obra de aprendizagem que é o saber do acontecimento. Vestígio desta obra de criação que é tocar o instante de revelação dos mundos.

Persistimos em nossas investidas, neste círculo de nossa aprendizagem, ao instante em que, pelo estado de arte, se pressente a doação de sentido. Imprimimos os traços da experiência de criação na paisagem escolar. De maneira esquiva percebemos, diminuta e consistente, nossa realização em obra. A partir destas considerações nos aproximaríamos de uma pesquisa em educação cujas metodologias se fariam artísticas.

\section{REFERÊNCIAS}

ALVES, N. Decifrando o pergaminho - o cotidiano na escola nas lógicas das redes cotidianas. In: OLIVEIRA, I. B e ALVES, N. Pesquisa no/do cotidiano das escolas - sobre redes de saberes. Rio de Janeiro: DP \& A, 2001. 
BARTHES, R. A Câmara Clara: nota sobre a fotografia. Rio de Janeiro: Nova Fronteira, 2012.

CERTEAU, M. de. A Invenção do Cotidiano: Artes de Fazer. $3^{\text {a }}$ ed., Petrópolis, RJ: Vozes, 1998.

DELEUZE, G. Diferença e Repetição. $2^{\text {a }}$ ed., Rio de Janeiro: Graal, 2006.

. Lógica do Sentido. $4^{\text {a }}$ ed., São Paulo: Perspectivas, 2007.

. Proust e os Signos. Rio de Janeiro: Forense Universitária, 2010.

DIAS, S. A Lógica do Acontecimento: Deleuze e a filosofia. Porto: Edições Afrontamentos, 1995.

DIDI-HUBERMAN, G. Diante da Imagem: questão colocada aos fins de uma história da arte,

São Paulo: Editora 34, 2013.

FOUCAULT, M. A Arqueologia do Saber. Petrópolis, RJ: Vozes, 1972.

GUINZBURG, C. Mitos, Emblemas e Sinais: morfologia e história. São Paulo: Companhia das

Letras, 1989.

HEIDEGGER, M. A Origem da Obra de Arte. São Paulo: Edições 70, 2010.

KRAUSS, R. O Fotográfico. Barcelona: Editorial Gustavo Gili, 2012.

MERLEAU-PONTY, M. O Visivel e O Invisível. São Paulo: Perspectivas, 2009.

RANCIÈRE, J. O Mestre Ignorante. $3^{\text {a }}$ ed., Belo Horizonte: Autêntica Editora, 2013.

SANTOS, R. C. Opus Dei. In: KIFFER, A., REZENDE, R. e BIDENTE, C., Experiência e Arte

Contemporânea. Rio de Janeiro: Circuito, 2012, v. 01, p. 91-95.

VICTÓRIO FILHO, A. A Arte na/da Educação: a invenção cotidiana da escola. Tese de

Doutorado, UERJ, 2005.

\footnotetext{
${ }^{i}$ Este trabalho tem como base uma comunicação realizada em Simpósio sobre Pesquisa em Educação e Metodologias Artísticas do 24o Encontro da ANPAP (Associação Nacional de Pesquisadores em Artes Plásticas).

ii Pedagogo pela UNIRIO. Obteve o título de mestre pelo PPGARTES/UERJ (2015), onde foi bolsista CAPES. Faz parte do grupo de pesquisa Estudos Culturais em Educação e Arte (UERJ), coordenado pelo prof. Dr. Aldo Victorio Filho. Dedica-se a pesquisar o entrecruzamento entre os dispositivos pedagógico e artístico, como, por seus exercícios, as aprendizagens e criações desveladas em acontecimento.

iii Atribuo a concepção de cotidiano a Michel de Certeau (1998).

iv Defendo, por outro lado, uma pluralidade de mundos que não cessam de se efetuar em verdade pelos prolongamentos do acontecimento de criação.

v Recorro aqui à leitura que Deleuze (2006, pg.82) desenvolve sobre a noção de mundo elaborada por Leibniz, onde o mundo pode ser concebido através daquilo que se exprime junto ao seu universo de possíveis. Essa expressão que se realiza pelo que é dado na atualidade como os possíveis dos nossos gestos, falas e percepções.

vi Tomo como referência sobre os estudos do cotidiano e as pesquisas narrativas, dentre outros trabalhos, os estudos de Alves (2001) e Victorio Filho (2005).

vii “(...) corre-se o risco de falar demais e de fazer calar tudo o que não deriva estritamente ao dispositivo; então se pensará mais alto que a pintura, com o risco de perder-se na transcendência de um modelo eidético - um universal abstrato do sentido - que não é menos redutor que o idealismo do modelo referencial" (DIDI-HUBERMAN, pg. 337, 2013).
} 
viii Tenho considerado a recolha dos traços como procedimento indispensável às formações discursivas e, por conseguinte, aos dispositivos de poder. Os princípios que regem tal procedimento são o princípio de raridade, exterioridade e acúmulo, como assim pontua Foucault (1972), sendo os traços o limiar de existência dos signos.

ix Localizado no centro do município do Rio de Janeiro, próximo à Central do Brasil, foi possível estar em contato com jovens de diferentes regiões da cidade e de outros municípios da região metropolitana. Boa parte de seus estudantes são moradores da zona norte e oeste, exigindo que as normalistas necessariamente transitem pela cidade, realizando extensos trajetos urbanos, antes de alcançar o colégio.

$\mathrm{x}$ Tenho como pressuposto da aprendizagem esta cumplicidade profunda: “'aprender' passa sempre pelo inconsciente, passa-se sempre no inconsciente, estabelecendo, entre a natureza e o espírito, o liame de uma cumplicidade profunda" (DELEUZE, 2006, pg. 237).

xi "Nunca se sabe como uma pessoa aprende; mas, de qualquer forma que aprenda, é sempre por intermédio de signos, perdendo tempo, e não pela assimilação de conteúdos”. (DELEUZE, 2010, pg. 21).

xii Didi-Huberman (2013, pg. 89) demonstra como a economia da salvação instaurada desde o surgimento da história da arte enquanto campo problemático está intimamente relacionada a uma economia da angustia. A imortalidade da obra e a fama do artista proclamada pela história da arte estão necessariamente relacionadas ao sepultamento de uma vastidão de obras e uma infinidade de artistas considerados menores.

xiii Sigo aqui as indicações de Heidegger (2010, pg. 181) “Quando a arte é o originário da obra, então, isto quer dizer que ela, em sua essência, deixa nascer na obra a co-pertença essencial dos que criam e dos que desvelam”.

xiv Considero as fotografias como o registro do traço luminoso deste contato entre o visível e o vidente, na relação com sua aparição no mundo (BARTHES, 2012) e seu próprio funcionamento semiótico (KRAUSS, 2012). 